\title{
Human Propionyl CoA Carboxylase: Some Properties of the Partially Purified Enzyme in Fibroblasts from Controls and Patients with Propionic Acidemia
}

\author{
Y. EDWARD HSIA, ${ }^{(31)}$ KATHERINE J. SCULLY, AND LEON E. ROSENBERG ${ }^{(32)}$ \\ Departments of Human Genetics and Pediatrics, Yale University School of Medicine, New Haven, Connecticut, USA
}

\section{Summary}

We report some properties of propionyl CoA carboxylase (PCC) partially purified from cultured human fibroblasts obtained from controls and several patients with propionic acidemia. A series of steps (Triton X-100 treatment, high speed centrifugation, ammonium sulfate precipitation, and density gradient centrifugation) led to 100 - to 300-fold purification of control enzyme. Control PCC had a molecular weight of nearly 700,000 , contained biotin, demonstrated a $\mathrm{pH}$ optimum at $8.0-8.5$, was activated by potassium, and followed Michaelis-Menten kinetics for each of its substrates. It was distinguished from acetyl CoA carboxylase immunologically as well as by differential purification.

Each of seven lines from patients with propionic acidemia had clearly detectable PCC activity which was less than $5 \%$ of that in control lines. Although yields were poor and purification less extensive than in control lines, mutant PCC was enriched 2- to 40fold by the same procedures employed for the control enzyme. Mutant enzyme had a $\mathrm{pH}$ optimum, ionic requirements, and substrate $K_{m}$ 's similar to those of control PCC, but was distinctly more labile to both cold and heat. These findings suggest that the markedly reduced activity of PCC in these patients results from a mutation in the PCC structural gene locus or loci which leads to the synthesis of altered enzyme protein molecules.

\section{Speculation}

Our results suggest that human propionyl $\mathrm{CoA}$ carboxylase has properties very similar to those of other mammalian propionyl CoA carboxylases. Further chemical studies with control enzyme and that from patients with propionic acidemia may help define the basis for the two major genetic complementation groups reported among propionyl $\mathrm{CoA}$ carboxylase deficient patients.

PCC (propionyl CoA: $\mathrm{CO}_{2}$ lyase (ADP) EC 6.4.1.3) is a key enzyme $(7,8,12,18-20)$ in the catabolic pathway for the threecarbon residue from isoleucine, threonine, methionine, valine (26), branched chain and odd carbon fatty acids, cholesterol, and thymine. It reversibly catalyzes the carboxylation of propionyl CoA to D-methylmalonyl CoA which is isomerized to succinyl $\mathrm{CoA}$ in two steps by methylmalonyl CoA racemase and methylmalonyl CoA mutase (12). PCC has been studied extensively in liver of ruminants $(12,18)$, and in rat liver mitochondria (19). In man, the activity of this enzyme has been measured in cultured fibroblasts (10), leukocytes (9), liver $(3,4,17)$, and amniotic fluid cells (5). It has been purified 20-fold from human liver mitochondria (4).

The important role of this enzyme in human intermediary metabolism is evident from the dire consequences of inherited PCC deficiency. Patients with defective PCC activity have elevated blood and úrine propionate levels (24), are susceptible to attacks of severe ketoacidosis, may develop hypoglycemia and hyperam- monemia (14), and also have intermittent hyperglycinemia. The condition can be lethal in infancy and can produce seizures and severe brain damage. Some patients with severe PCC deficiency, however, have mild and even benign clinical manifestations (15, 20).

Successful partial purification of PCC (100- to 300-fold) from cultured normal human skin fibroblasts has enabled us to define some of its biochemical properties. Comparison of these properties with those of PCC from cultured fibroblasts of patients with propionic acidemia has provided evidence that PCC deficiency in these patients results from the synthesis of a structurally altered enzyme (11).

\section{MATERIALS AND METHODS}

Propionyl CoA and acetyl CoA were prepared as described previously (10), except that the propionic anhydride-coenzyme A solution was neutralized with sodium hydroxide to avoid contamination with potassium or bicarbonate. The anti-chick ACC antibody was a generous gift from Dr. Philip Majerus of Washington University, St. Louis, MO; avidin was purchased from General Biochemicals; urease, catalase, and thyroglobulin were purchased from Sigma Chemicals; other reagents were obtained as reported previously (10).

\section{PATIENTS.WITH PCC DEFICIENCY}

A. G. $(1,10)$, the sister of the first-described patient with "ketotic hyperglycinemia", has had attacks of ketoacidosis successfully treated by diet, with normal physical and intellectual growth. $R$. $H$., a girl, presented with ketoacidosis and failure to thrive. She had irreversible brain damage by the time PCC deficiency was diagnosed at age 1 yr. G. S. (14), a black male, whose older sister died in infancy of a similar clinical syndrome, had intermittent ketoacidosis complicated by severe hyperammonemia. He suffered from recurrent attacks of seizures and coma, had evidence of brain damage, and died at the age of $4 \mathrm{yr} . P$. C. (14), a girl, presented with ketoacidosis and moderate hyperammonemia. She had seizures, attacks of coma, and died with irreversible acidosis at the age of 2 yr. $N$. B. (15), a moderately retarded girl with three unaffected siblings, presented with seizures and hyperglycinemia at age 9 months. She exhibited no ketoacidosis or hyperammonemia unless given a high protein load. $N . M$. (20) a 4-year-old Mennonite boy with two clinically normal siblings, had hyperglycinemia associated with seizures and retardation, but no ketoacidosis. His 9-year-old sister, $K$. M., was entirely normal clinically, yet had equally marked deficiency of PCC (20).

\section{CULTURED FIBROBLASTS}

Punch biopsies of the skin were obtained, with informed consent and generally from the flexor surface of the forearm, from these seven PCC-deficient patients and from eight normal adult volun- 
teers. The biopsies were cultured as reported previously $(8,20)$. Between the 10th and 28th passages, cells were harvested at confluence by treatment with $0.25 \%$ trypsin and centrifugation at $110 \times g$. The cell pellets were resuspended and washed first in

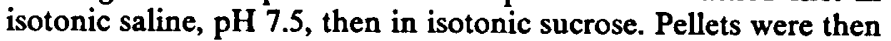
processed immediately, or stored frozen at $-68^{\circ} \mathrm{C}$ for up to 6 weeks.

\section{ENZYME PURIFICATION}

All purification steps were carried out at $+4^{\circ} \mathrm{C}$. Cells were broken by exposure to distilled water for $10 \mathrm{~min}$, addition of 0.05 $\mathrm{M}$ Tris buffer, $\mathrm{pH} 7.5$, containing $0.001 \mathrm{M}$ EDTA, and gentle mechanical disruption with three strokes of a Potter-Elvehjem homogenizer. Unbroken cells and cell debris were removed by centrifugation at $250 \times g$ for $15 \mathrm{~min}$, retreated with distilled water as above, and centrifuged again at $250 \times \mathrm{g}$. Reduced glutathione (GSH) was added to the combined supernatants to a concentration of $0.005 \mathrm{M}$, and the preparation was centrifuged at $118,000 \times \mathrm{g}$ for $120 \mathrm{~min}$. The pellet was resuspended in the above medium plus $0.3 \%(v / v)$ Triton X-100, and stirred for $30 \mathrm{~min}$; it was then centrifuged at $10,000 \times g$ for $20 \mathrm{~min}$. A saturated ammonium sulfate solution was added to the supernatant with stirring over 60 min until $35 \%$ saturation was reached. This preparation was centrifuged at $10,000 \times g$ for $30 \mathrm{~min}$ and the supernatant was brought to $50 \%$ saturation of ammonium sulfate. The preparation from control cells could be stored at this stage at $-68^{\circ} \mathrm{C}$ for several weeks without loss of enzyme activity. Further purification was achieved by centrifuging the $50 \%$ ammonium sulfate suspension at $10,000 \times g$ and redissolving the protein precipitate in $0.05 \mathrm{M}$ Tris buffer (pH 7.5) containing 0.001 M EDTA, 0.005 M GSH, $0.1 \%(v / v)$ Triton X-100, and $1 \%(v / v)$ glycerol. The preparation was then dialyzed overnight against the same solution to remove ammonium sulfate. The dialyzed enzyme preparation was centrifuged at $450 \times g$ for $10 \mathrm{~min} ; 0.2-0.3 \mathrm{ml}$ of the supernatant was layered over a $5 \mathrm{ml}, 5-20 \%$ linear concentration gradient of sucrose $(w / v)$ or glycerol $(v / v)$ in the buffer mentioned above, and centrifuged at $130,000 \times g$ for $4 \mathrm{hr}$ in a Beckman (SW 50.1) swinging bucket rotor. Aliquots of $0.2 \mathrm{ml}$ were collected from the gradient using an ISCO density gradient fractionator (Model 640). The three or four aliquots containing the bulk of the enzyme activity were pooled for biochemical studies.

\section{CARBOXYLASE ASSAYS}

PCC was assayed, as described previously, by measurement of $\left[{ }^{14} \mathrm{C}\right]$ bicarbonate incorporation, in the presence of propionyl CoA, into a nonvolatile, " $\mathrm{CO}_{2}$-fixed" state (9). The incubation mix contained $5 \%(\mathrm{v} / \mathrm{v})$ glycerol, $1 \%(\mathrm{v} / \mathrm{v})$ Triton X-100, $0.05 \mathrm{M}$ Tris (pH 8.0), $0.005 \mathrm{M}$ GSH, $0.002 \mathrm{M}$ neutralized adenosine triphosphate (ATP), $0.01 \mathrm{M}$ magnesium chloride, $0.025 \mathrm{M}$ potassium chloride, $0.003 \mathrm{M}$ propionyl $\mathrm{CoA}$, and $0.01 \mathrm{M}$ sodium $\left[{ }^{14} \mathrm{C}\right]$ bicarbonate $(12.2 \mu \mathrm{Ci} / \mu \mathrm{mole})$, with $0.02-0.05 \mathrm{ml}$ of the protein preparation, in a final volume of $0.1 \mathrm{ml}$. Incubation $\left(37^{\circ} \mathrm{C}\right)$ was timed from addition of the $\left[{ }^{14} \mathrm{C}\right]$ bicarbonate and was terminated after 5 $60 \mathrm{~min}$ by addition of $0.05 \mathrm{ml} \mathrm{10 \%}$ trichloroacetic acid. All assays were in duplicate and included a blank containing no propionyl CoA. One unit of PCC activity is defined as that catalyzing the formation of 1 nmole of product (or of fixing 1 nmole of $\mathrm{CO}_{2}$ ) per minute, and specific activity (SA) is presented as units/mg protein.

Acetyl CoA carboxylase (ACC) activity was also estimated by incorporation of $\left[{ }^{14} \mathrm{C}\right]$ bicarbonate, in the presence of acetyl CoA and its allosteric activator; citrate, into either malonate or into a nonvolatile, $\mathrm{CO}_{2}$-fixed state (16). Recovery of $\left[{ }^{14} \mathrm{C}\right]$ malonate in the presence of carrier malonate after ether extraction and paper chromatography (10) was $50 \%$ in the absence of citrate and $70 \%$ in the presence of citrate. Replicate portions of cell extracts were first incubated for $30 \mathrm{~min}$ at $37^{\circ} \mathrm{C}$, with and without $0.01 \mathrm{M}$ sodium citrate, in $0.03 \mathrm{M}$ Tris ( $\mathrm{pH}$ 7.6), $0.001 \mathrm{M}$ EDTA, $0.01 \mathrm{M}$ GSH, $0.01 \mathrm{M}$ magnesium chloride, and $0.6 \mathrm{mg} / \mathrm{ml}$ bovine serum albumin. The reaction, in a final volume of $1.0 \mathrm{ml}$ or $0.1 \mathrm{ml}$, was initiated by addition of $0.001 \mathrm{M}$ ATP, $0.0015 \mathrm{M}$ acetyl CoA, and $0.02 \mathrm{M}$ sodium $\left[{ }^{14} \mathrm{C}\right]$ bicarbonate $(4.5 \mu \mathrm{Ci} / \mu$ mole $)$ and proceeded for $10 \mathrm{~min}$ at $37^{\circ} \mathrm{C}$. The reaction was stopped by addition of alkali for $\left[{ }^{14} \mathrm{C}\right]$ malonate extraction (10), or by addition of acid for $\mathrm{CO}_{2}$ fixation $(9,16)$. All assays were in duplicate and included a blank containing no acetyl CoA. SA was defined as PCC.

Protein determination by the standard Lowry procedure, as used previously (10), was satisfactory for high protein concentrations in crude cell extracts. Because Tris buffer (21) and Triton X100 (28) interfered with the Lowry reaction for the very low protein concentrations in the density gradient fractions, a fluorometric assay was used (27) with bovine serum albumin as the standard.

\section{PROPERTIES OF PCC}

For the Michaelis-Menten kinetic studies, the potassium concentration was maintained at $0.025 \mathrm{M}$, and one substrate was varied at a time. When bicarbonate was the variable substrate, the $\mathrm{SA}$ of $\left[{ }^{14} \mathrm{C}\right]$ bicarbonate was increased to $50 \mu \mathrm{Ci} / \mu$ mole at the lowest bicarbonate concentrations.

For thermostability experiments, $0.04 \mathrm{ml}$ of cell extracts or partially purified preparations, in the final buffer, were transferred to preheated tubes in a water bath at the test temperature (37$58^{\circ} \mathrm{C}$ ) for timed intervals $(30 \mathrm{sec}-60 \mathrm{~min})$, then the tubes were removed and immersed in ice; control portions were retained in similar tubes in ice. PCC was then assayed by adding $0.06 \mathrm{ml}$ of prewarmed reagent mixture to these (rewarmed) tubes for incubation at $37^{\circ} \mathrm{C}$ for $10 \mathrm{~min}$.

Anti-ACC antibody, prepared against chick enzyme ( $1 \mu 1$ neutralized 2500 units of chick ACC activity at $\left.25^{\circ} \mathrm{C}\right)(16)$, was tested against $0.04 \mathrm{ml}$ of protein preparations for its ability to inhibit PCC and ACC activity.

\section{AVIDIN INHIBITION}

Avidin inhibition of carboxylase activity was tested by preincubating $0.02 \mathrm{ml}$ of the cell fractions with $0.02 \mathrm{ml}$ of mixtures of avidin and biotin for $10 \mathrm{~min}$ at $37^{\circ} \mathrm{C}(1 \mathrm{U}$ avidin inactivates $1 \mu \mathrm{g}$ biotin), followed by adding $0.06 \mathrm{ml}$ of the appropriate reagent mixture for assay of PCC or ACC activity. For ACC activity, avidin treatment was performed before the addition of citrate, avoiding the protective effect of citrate on avidin inhibition of ACC (23).

\section{RESULTS}

\section{CONTROL FIBROBLASTS}

Partial Purification. We observed initially that more PCC activity was found in cell extracts prepared by lyophilization than from preparations obtained by freeze-thawing, acetone precipitation, or sonication. As noted in the results of a representative experiment shown in Table 1, treatment of the crude cell lysate from three roller bottles with the detergent, Triton $\mathrm{X}-100$, resulted in an approximately 2 -fold increase in both specific activity and total enzyme activity. SA was increased 2-fold further in the pellet obtained after $118,000 \times g$ centrifugation. Subsequent ammonium sulfate precipitation and density gradient centrifugation yielded an enzyme preparation purified 300 -fold with a yield of $11 \%$

As noted in Table 2, purification of PCC from five different control lines gave similar, but not identical, results. Initial SA ranged from $0.34-1.42 \mathrm{U} / \mathrm{mg}$; final SA from 53-175 U/mg. Overall purification ranged from 110 - to 300 -fold with yields from 11$17 \%$.

Physical Properties of Partially Purified PCC. Despite attempts to stabilize the enzyme by addition of $10 \%(\mathrm{w} / \mathrm{v})$ bovine serum albumin, $1 \%(\mathrm{v} / \mathrm{v})$ glycerol, $0.1 \mathrm{mg} / \mathrm{ml}$ biotin, or $0.003 \mathrm{M}$ propionyl CoA, PCC activity from the peak density gradient fractions deteriorated markedly overnight at $4^{\circ} \mathrm{C}$, thereby making it necessary to characterize this fraction on the day it was prepared. 
Table 1. Partial purification of propionyl CoA carboxylase from normal human fibroblasts ${ }^{1}$

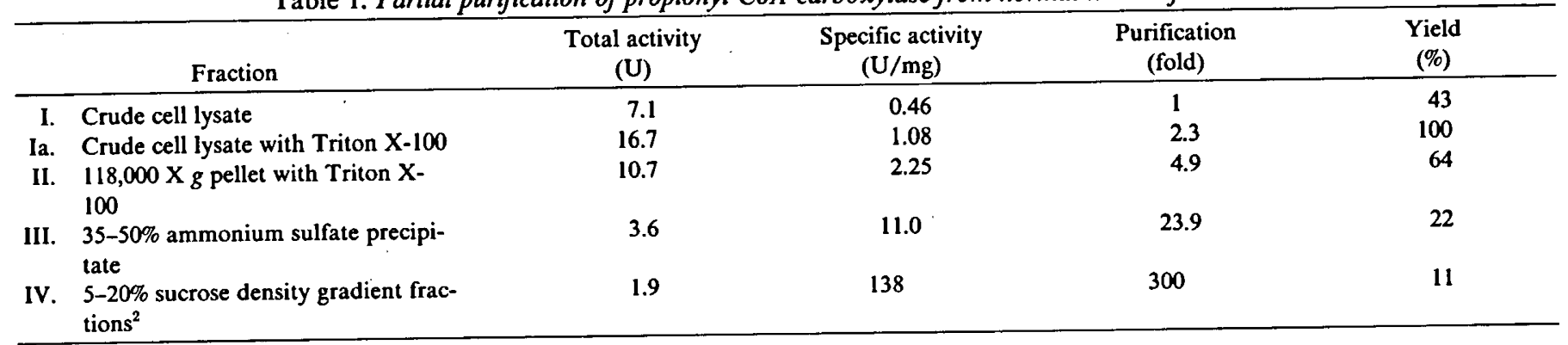

\footnotetext{
${ }^{1}$ Results shown are representative of several experiments with a single control line.
}

${ }^{2}$ Pooled PCC activity from four adjacent fractions.

Table 2. Partial purification of propionyl CoA carboxylase from several control cell lines

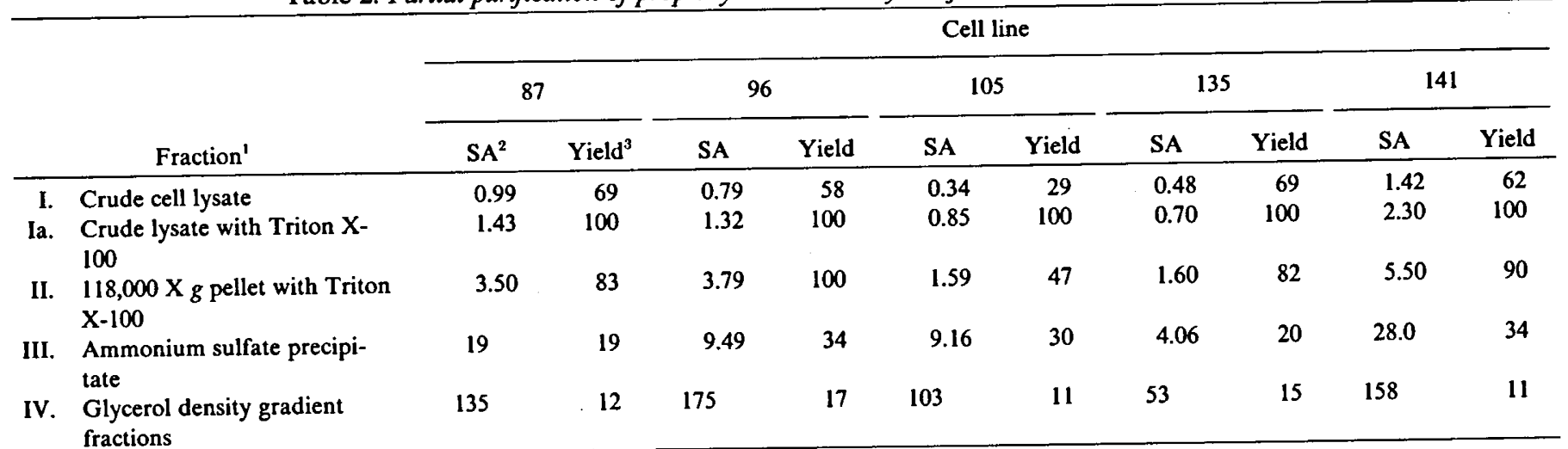

'See Methods and Table 1 for additional details.

${ }^{2}$ Specific activity reported in $\mathrm{U} / \mathrm{mg}$ protein.

${ }^{3}$ Yield expressed as percent of maximal recovered in crude extract in presence of Triton X-100.

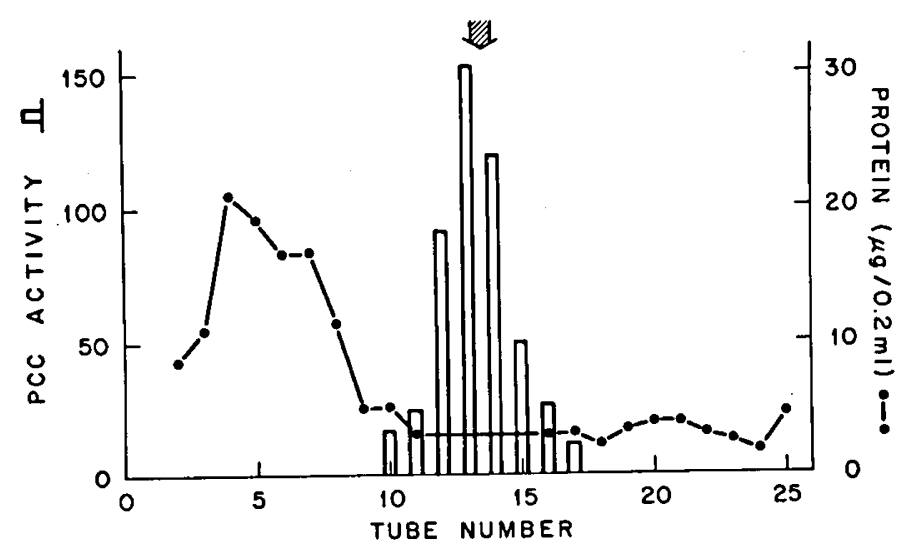

Fig. 1. Distribution of control PCC activity after 5-20\% sucrose density gradient centrifugation. PCC specific activity, shown in vertical bars on the left ordinate, is expressed as units/mg protein. Total protein (right ordinate) is shown as solid circles. The arrow indicates the location of the sedimentation peak of porcine thyroglobulin in this system. The four fractions with the highest PCC activity were pooled as Fraction IV in the purification scheme.

The molecular weight of the partially purified enzyme was estimated by density gradient centrifugation using urease (MW483,000 ), catalase (MW-232,000) and porcine thyroglobulin (MW$669,000)$ as markers (2). As noted in Figure 1, sedimentation of PCC activity corresponded closely to that of thyroglobulin, a result in good agreement with the $\mathrm{MW}$ of 700,000 obtained previously for crystalline PCC from pig heart (12).

Biochemical Properties of Partially Purified PCC. PCC activity in Fraction IV (see Table 1) was linear with time for $30 \mathrm{~min}$ and with protein content over the range employed. As expected, activ- ity depended on the presence of propionyl CoA, ATP, and bicarbonate. Addition of potassium at concentrations of $0.01 \mathrm{M}$ and above stimulated activity 10 -fold. PCC activity revealed a broad pH optimum between 8.0 and 8.5 , and neither glycerol, sucrose, Triton X-100, nor ammonium sulfate interfered.

As shown in Figure 2, partially purified PCC demonstrated Michaelis-Menten kinetics for each of its substrates. At ATP concentrations greater than $0.020 \mathrm{M}$, activity was inhibited; substrate inhibition was not observed for propionyl CoA or bicarbonate. The estimated $\mathrm{K}_{\mathrm{m}}$ 's for the three substrates are as follows: propionyl CoA, $1.7 \times 10^{-3} \mathrm{M}$; bicarbonate, $4.5 \times 10^{-3} \mathrm{M}$; ATP, $0.9 \times 10^{-3} \mathrm{M}$.

PCC was unstable to heating. Incubation of Fraction IV at temperatures above $50^{\circ} \mathrm{C}$ for $5 \mathrm{~min}$ resulted in marked loss of activity. At $54^{\circ} \mathrm{C}$, the $t_{12}$ for activity loss was $15 \mathrm{~min}$; at $58^{\circ} \mathrm{C}$, the $t_{12}$ was 3 min. PCC activity was even less stable in crude extracts, its $\mathrm{t}_{1 / 2}$ at $54^{\circ} \mathrm{C}$ being $5 \mathrm{~min}$.

Biotin-Avidin Interactions. Neither addition of biotin to the growth medium nor incubation of crude cell extracts or partially purified enzyme fractions with this cofactor enhanced PCC activity. As expected, incubation of crude extracts with avidin inhibited PCC activity markedly (Fig. 3); this inhibition was prevented by exposing the avidin to increasing amounts of biotin before incubating it with PCC fractions.

$A C C$ Activity and Anti-ACC. ACC activity, defined as citrateactivated $\left[{ }^{14} \mathrm{C}\right]$ bicarbonate incorporated in the presence of acetyl CoA was present in crude cell lysates and in $118,000 \times g$ pellets prepared from them (Table 3); it was undetectable in the $35-50 \%$ ammonium sulfate precipitate. Additional evidence that the ACC and PCC activities reflected the presence of different proteins came from antibody studies. Addition of specific anti-chick liver ACC antibody to a $118,000 \times g$ pellet containing both $A C C$ and PCC activities resulted in 55\% loss of ACC activity, but no loss of PCC activity (Table 4). 

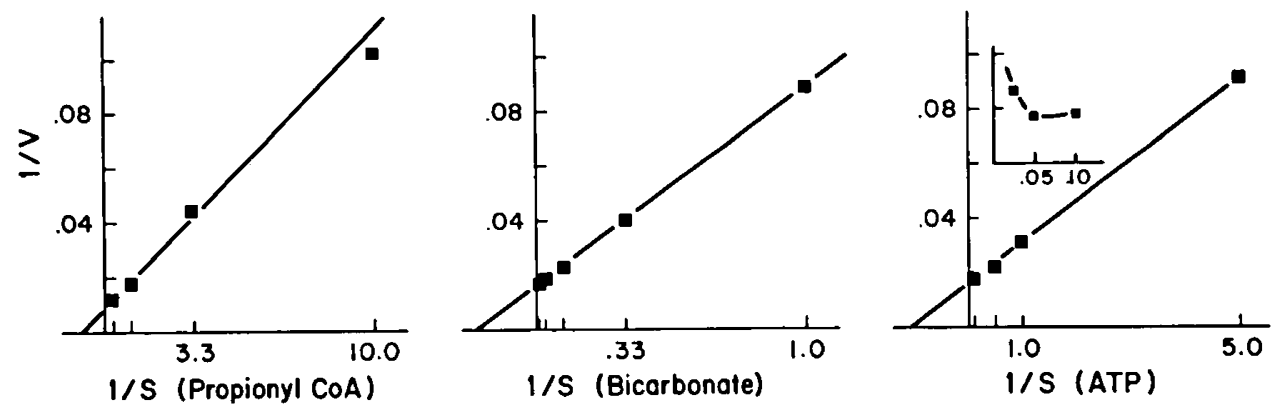

Fig. 2. Double reciprocal plots of PCC activity in Fraction IV from control cells versus substrate concentrations. The inset in the ATP plot shows the inhibitory effect of high concentrations of this nucleotide. All substrate concentrations are expressed as $10^{-3} \mathrm{M}$. See text for details.

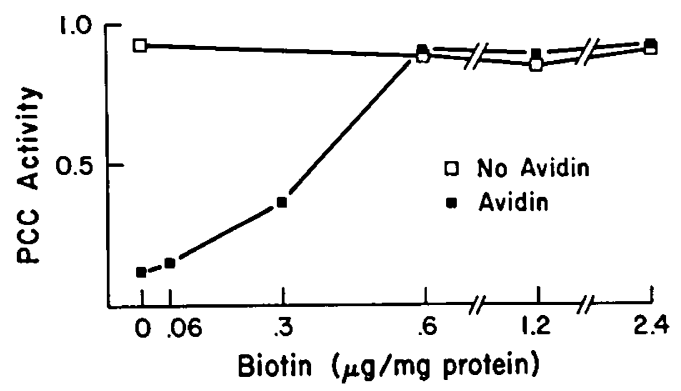

Fig. 3. Effect of addition of avidin and/or biotin on PCC specific activity (units/mg protein) in crude lysates of control cells. One unit of avidin was added to some lysates (closed squares) 5 min before PCC assay. Biotin, in the amounts shown on the abscissa, was added to both avidintreated or avidin-untreated lysates $10 \mathrm{~min}$ before assay.

\section{PCC DEFICIENT FIBROBLASTS}

PCC Activity. Each of the seven cell lines from patients with propionic acidemia had much reduced PCC activity. Although considerable variation was noted among preparations from the same cell line, crude extracts of these lines always had detectable PCC activity at values less than 5\% of the control mean. This mutant cell activity was poorly preserved during storage. When crude extracts of control cells were kept at $4^{\circ} \mathrm{C}$ for up to $24 \mathrm{hr}$, no loss of PCC activity was noted; similar treatment of mutant cell extracts led to $70-90 \%$ loss of activity. Frozen cell pellets were no more stable. PCC activity in one mutant line decreased by $75 \%$ when intact cell pellets were stored at $-20^{\circ} \mathrm{C}$ before lysis and assay. Therefore, all subsequent experiments with mutant cells were conducted with cells harvested immediately before use.

Partial Purification. As noted in Table 5, the purification procedure employed for control lines was much less effective in recovering PCC activity from mutant cells. Triton X-100 treatment failed to increase PCC SA in crude lysates of mutant cells and led to some loss in total activity in two of the four lines examined (A. G. and G. S.). Although PCC activity from mutant cells was found in the same centrifugation fractions, ammonium sulfate cuts, and density gradient fractions as those in control cells, at each step, enrichment of activity and yield were much poorer than in control cells. Much of the loss took place before ammonium sulfate treatment, but omission of detergent treatment and high speed centrifugation before addition of ammonium sulfate gave no appreciable increase in purification or yield. Furthermore, addition of glycerol, bovine serum albumin, propionyl CoA, ATP, or biotin failed to increase PCC recovery. In the four mutant lines used, PCC SA after glycerol density gradient centrifugation ranged from $0.12-1.64 \mathrm{U} / \mathrm{mg}$, reflecting only 2 - to 40 -fold purification. At this stage the yield was only $0.1-1.0 \%$ of starting activity.

Biochemical and Physical Properties. Many characteristics of the partially purified PCC in Fraction IV from mutant lines were indistinguishable from those for control enzyme. Thus, the mutant enzymes appeared to have the same molecular weight, pH optimum, and affinity for all three substrates as did control PCC.
Table 3. Acetyl CoA carboxylase activity in control fibroblasts

\begin{tabular}{cllc}
\hline \multicolumn{1}{c}{ Fraction } & \multicolumn{1}{c}{ Conditions $^{\prime}$} & $\begin{array}{c}\text { Specific activity } \\
(\mathrm{U} / \mathrm{mg})\end{array}$ \\
\hline I. & Crude cell lysate & Complete system & 0.032 \\
& & - Citrate & 0.002 \\
& & - Acetyl CoA & 0.003 \\
II. $118,000 \mathrm{X}$ g pellet & Complete system & 0.001 \\
& & - Citrate & 0.278 \\
III. Ammonium sulfate & Complete system & 0.004 \\
& precipitate & - Citrate & Undetectable \\
\hline
\end{tabular}

'See Methods for details.

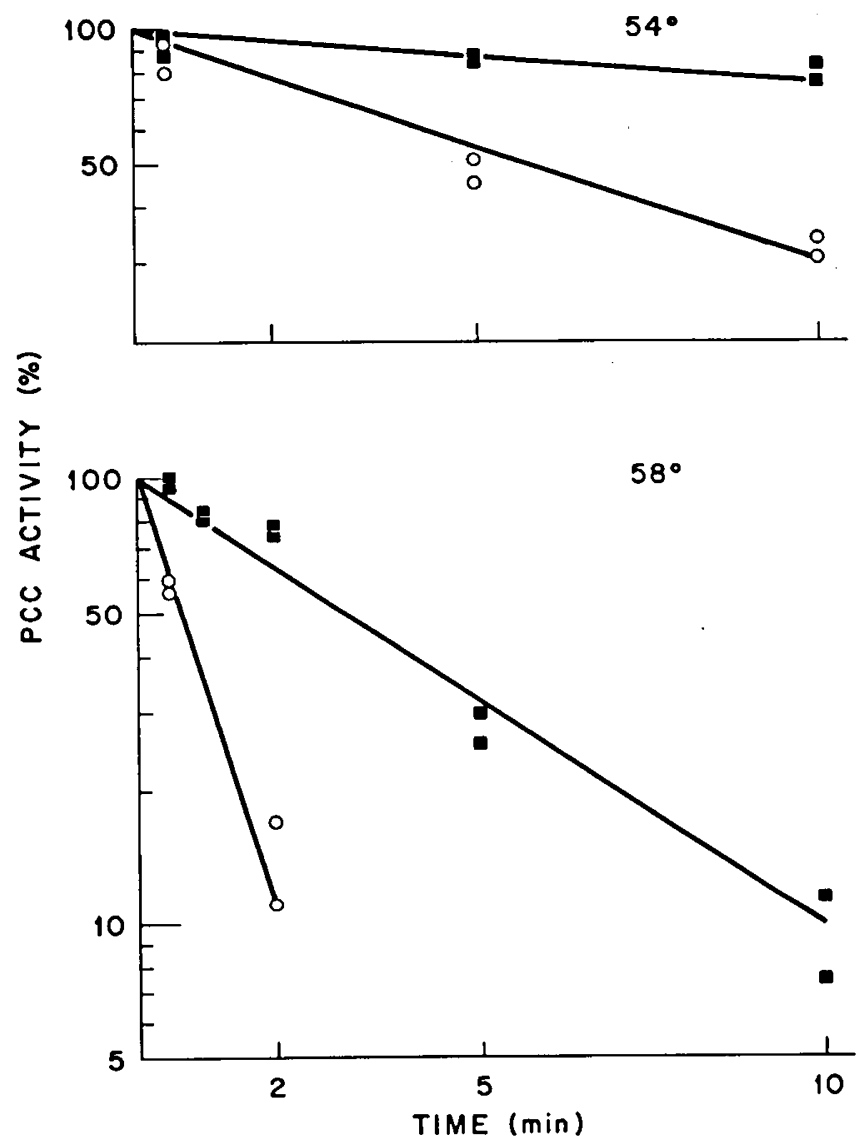

Fig. 4. Time course of thermal inactivation of $P C C$ activity in Fraction IV from representative control (closed squares) and PCC-deficient lines (open circles). PCC activity is expressed as percent of that determined at $37^{\circ} \mathrm{C}$ for each fraction. The upper panel shows result of heating at $54^{\circ} \mathrm{C}$ for each fraction. The upper panel shows results of heating at $54^{\circ} \mathrm{C}$ while the lower panel shows effects of heating at $58^{\circ} \mathrm{C}$. Comparable amounts of total protein were used in the assays of control and mutant enzyme. Duplicate values are shown throughout. 
Table 4. Effect of anti-acetyl CoA carboxylase antibody on ACC and PCC activities in control cell extracts

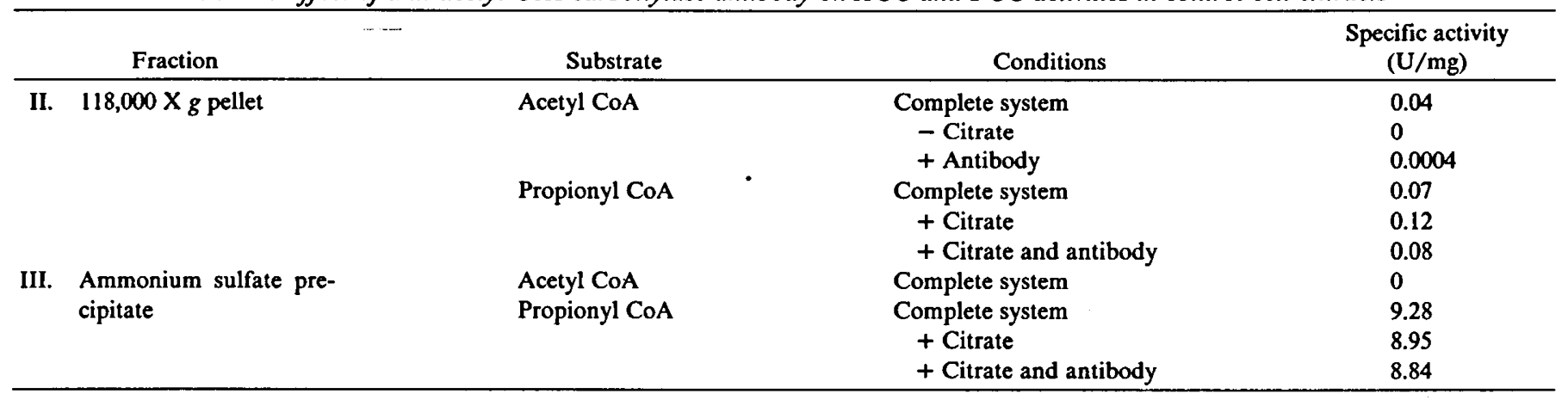

Table 5. Partial purification of propionyl CoA carboxylase from several PCC-deficient cell lines

\begin{tabular}{|c|c|c|c|c|c|c|c|c|c|}
\hline \multirow{3}{*}{\multicolumn{2}{|c|}{ Fraction ${ }^{1}$}} & \multicolumn{8}{|c|}{ Cell lines } \\
\hline & & \multicolumn{2}{|c|}{ A. $\mathbf{G}$. } & \multicolumn{2}{|c|}{ N. B. } & \multicolumn{2}{|c|}{ G. $\mathbf{S}$. } & \multicolumn{2}{|c|}{ P. C. } \\
\hline & & $\mathrm{SA}^{2}$ & Yield $^{3}$ & SA & Yield & SA & Yield & SA & Yield \\
\hline I. & Crude cell lysate & 0.02 & 100 & 0.08 & 85 & 0.06 & 100 & 0.04 & 100 \\
\hline Ia. & $\begin{array}{l}\text { Crude cell lysate with Triton } \\
X-100\end{array}$ & 0.01 & 63 & 0.09 & 100 & 0.02 & 36 & 0.04 & 100 \\
\hline II. & $\begin{array}{l}118,000 \times g \text { pellet with Tri- } \\
\text { ton } X-100\end{array}$ & 0.002 & 3 & 0.02 & 4.5 & 0.02 & 11 & 0.01 & 4 \\
\hline III. & $\begin{array}{l}\text { Ammonium sulfate precipi- } \\
\text { tate }\end{array}$ & 0.02 & 2 & 0.06 & 2.5 & 0.07 & 3 & 0.02 & 3 \\
\hline IV. & $\begin{array}{l}\text { Glycerol density gradient } \\
\text { fractions }\end{array}$ & 0.28 & 0.9 & 1.11 & 1 & 0.12 & 0.1 & 1.62 & 0.5 \\
\hline
\end{tabular}

\footnotetext{
'See Methods and Table 1 for details. See Table 2 for comparison with results in control lines.

${ }^{2}$ Specific activity reported in $\mathrm{U} / \mathrm{mg}$ protein.

${ }^{3}$ Yield expressed as percent of maximal activity recovered in crude cell extract in presence or absence of Triton X-100.
}

Furthermore, mutant PCC activity was not enhanced by addition of biotin to the growth medium, extraction buffers, or assay medium, and was, as in control preparations, inhibited markedly by prior exposure to avidin. Significantly, SA of ACC in mutant extracts was similar to that of controls, and addition of anti-ACC antibody failed to affect the residual PCC activity found in mutant lysates or fractions thereof.

The thermostability of mutant PCC was, however, consistently and distinctly reduced when compared to that of control enzyme at all temperatures studied above $50^{\circ} \mathrm{C}$. These differences are shown most clearly in the time-dependent heating studies shown in Figure 4. At $54^{\circ} \mathrm{C}$, control and mutant PCC activity decayed with a $t_{12}$ of 3 and 0.5 min, respectively. Thermolability of mutant PCC was unaffected by addition of appropriate enzyme substrates, biotin, glycerol, bovine serum albumin, or heat-inactivated control cell extracts.

\section{DISCUSSION}

In the early 1960's, PCC was purified to homogeneity from pig heart (12) and to near homogeneity from bovine liver $(7,8)$. From this work, a distinct, yet still incomplete picture of the mammalian enzyme emerged. Mammalian PCC is a mitochondrial protein with a molecular weight approximating 700,000 . Because it contains four biotinyl prosthetic groups per molecule, and because other mammalian biotin-dependent enzymes have been shown to be oligomeric, it seems likely that PCC is composed of four protomers with one biotin residue per protomer. Although the precise subunit structure of the protomer and reaction mechanism remain obscure, $P C C$ is activated by potassium ions and catalyzes the ATP-dependent carboxylation of propionyl CoA by a concerted mechanism which follows Michaelis-Menten kinetics for each of its substrates. The enzyme has a broad pH optimum between 8.0 and 8.5 , and the following estimated substrate $K_{m}$ 's:
$0.25 \times 10^{-3} \mathrm{M}$ for propionyl CoA; $2.0 \times 10^{-3} \mathrm{M}$ for bicarbonate; and $0.05 \times 10^{-3} \mathrm{M}$ for ATP $(7,8,12)$.

Despite having achieved only a partial purification of PCC from normal human fibroblasts, our results indicate that the human enzyme shares many similarities with its counterparts in other animal tissues. First, the human enzyme has a molecular weight comparable to that of the pig heart enzyme. Second, human PCC is avidin-inhibitable and this effect can be overcome by prior reaction of the avidin with biotin, indicating that human fibroblast PCC contains one or more biotin prosthetic groups. Third, it is activated by potassium and has $\mathbf{K}_{m}$ 's for each of its three substrates which agree within an order of magnitude with those found for purified PCC's. Fourth, its pH optimum is very similar to that of the porcine and bovine enzyme.

Although PCC activity in cell lysates from each patient with propionic acidemia was less than $5 \%$ that found in control lines, invariably some residual enzyme activity was detectable. That this residual PCC activity does not merely reflect cross-carboxylation of propionyl CoA by a second, biotin-dependent enzyme, acetyl CoA carboxylase, (ACC) was established in two ways. First, citrate-activated ACC activity was lost from both control and mutant cell lines during the ammonium sulfate treatment step, yet propionyl CoA carboxylation was enhanced by this purification procedure. Second, addition of anti-ACC antibody had no effect on residual PCC activity found in mutant lines whereas it inactivated much of the detectable ACC activity.

It could be argued that the residual PCC activity found in mutant cells reflects much reduced amounts of normal enzyme. The mutant enzyme was found in the same fractions during purification as the control, was inhibited by avidin, had a similar sedimentation pattern upon density gradient centrifugation and had comparable substrate $K_{m}$ 's to those of the normal enzyme. This thesis is refuted by two observations, however. First, mutant PCC was noted to be cold labile, while control enzyme was not. 
This property led to major problems in storing and purifying the mutant enzyme. Second, mutant PCC was much more thermolabile than its normal counterpart. This lability was demonstrable in partially purified fractions as well as crude extracts, thus appearing to be an intrinsic property of the mutant enzyme. Clearly, additional chemical and physical properties of the mutant enzyme must be studied to confirm the physical evidence just mentioned. Nonetheless, our findings lead us to conclude that PCC deficiency in the patients studied results from one or more mutations of the structural gene for PCC which lead, in turn, to structurally altered enzyme molecules whose affinity for substrates is comparable to that of controls, but whose in vivo stability is markedly impaired.

\section{REFERENCES AND NOTES}

1. Brandt, I. K., Hsia, Y. E., Clement, D. H., and Provence, S. A.: Propionicacidemia (ketotic hyperglycinemia): dietary treatment resulting in normal growth and development. Pediatrics, 53: 391 (1974).

2. Darnell, D. W., and Klotz, I. M.: Protein subunits: a table (revised edition). Arch Biochem. Biophys., 149: 1 (1972)

3. Frenkel, E. P., and Kitchens, R. L.: Intracellular localization of hepatic propionyl CoA carboxylase and methylmalonyl CoA mutase in humans and normal and vitamin $B_{12}$ deficient rats. Brit. J. Haematology, 31: 501 (1975).

4. Giorgio, A. J., and Whitaker, T. R.: Some properties of propionyl CoA carboxylase partially purified from human liver. Biochem. Med., 7: 473 (1973).

5. Gompertz, D., Goodey, P. A., Thom, H., Russell, G., Johnston, A. W., Mellow D. H., MacLean, M. W., Ferguson-Smith, M. E., and Ferguson-Smith, M.A.: Prenatal diagnosis and family studies in a case of propionicacidemia. Clin. Genet., 8: 244 (1975).

6. Gravel, R. A., Lam, K.-F., Scully, K. J., and Hsia, Y. E.: Genetic complementation of propionyl-CoA carboxylase deficiency in cultured human fibroblasts. Am. J. Human Genet., 29: 378 (1977)

7. Halenz, D. R., Feng, J. Y., Hegre, C. S., and Lane, M. D.: Some enzymic properties of mitochondrial propionyl carboxylase. J. Biol. Chem., 237: 2140 (1962).

8. Halenz, D. R., and Lane, M. D.: Properties and purification of mitochondrial propionyl carboxylase. J. Biol. Chem., 235: 878 (1960).

9. Hsia, Y. E., and Scully, K. J.: Propionicacidemia: diagnosis by enzyme assay in frozen leukocytes. J. Pediatr., 83: 625 (1973)

10. Hsia, Y. E., Scully, K. J., and Rosenberg, L. E.: Inherited propionyl CoA carboxylase deficiency in "ketotic hyperglycinemia." J. Clin. Invest., 50: 127 (1971).

11. Hsia, Y. E., Scully, K. J., and Rosenberg, L. E.: Propionicacidemia: biochemical characterization of mutant propionyl $\mathrm{CoA}$ carboxylase. Amer. J. Human Genet., (abstract) 25: 34a (1973).

12. Kaziro, Y., and Ochoa, S.: The metabolism of propionic acid. Adv. Enzymol., 26: 283 (1964)

13. Kim, Y. J., and Rosenberg, L. E.: On the mechanism of pyridoxine responsive homocystinuria. II. Properties of normal and mutant cystathionine $\beta$-synthase from cultured fibroblasts. Proc. Natl. Acad. Sci., 7I: 4821 (1974).

14. Landes, R. D., Avery, G. B., Walker, F. A., and Hsia, Y. E.: Propionyl CoA carboxylase deficiency (propionicacidemia): another cause of hyperammonemia. Pediatr. Res., (abstract) 6: 394 (1972).

15. Mahoney, M. J., Hsia, Y. E., and Rosenberg, L. E.: Propionyl CoA carboxylase deficiency (propionicacidemia): a cause of nonketotic hyperglycinemia. Pediatr. Res., (abstract) 5: 395 (1971).

16. Majerus, P. W., and Kilburn, E.: Acetyl coenzyme A carboxylase: the roles of synthesis and degradation in regulation of enzyme levels in rat liver. J. Biol. Chem., 244: 6254 (1969).

17. Morrow, G., Lebowitz, J., Revsin, R., and Giles, H.: Propionate metabolism in fetal livers of 15 to 19 weeks' gestation. Amer. J. Obstet. Gynecol., 121: 269 (1975).

18. Moss, J., and Lane, M. D.: The biotin-dependent enzymes. Adv. Enzymol., 35: 321 (1971).

19. Neujahr, H. Y., and Mistry, S. P.: Activation of mitochondrial propionyl CoA carboxylase. Acta Chem. Scand., 17: 1140 (1963).

20. Paulsen, E. P., and Hsia, Y. E.: Asymptomatic propionicacidemia: variability of clinical expression in a Mennonite kindred. Amer. J. Human Genet., (abstract) 26: 66a (1974).

21. Rej, R., and Richards, A. H.: Interference by Tris buffer in the estimation of protein by the Lowry procedure. Anal. Biochem., 62: 240 (1974).

22. Rosenberg, L. E.: Disorders of propionate, methylmalonate, and cobalamin metabolism. In: J. B. Stanbury, J. B. Wyngaarden, and D. S. Fredrickson: The Metabolic Basis of Inherited Disease, 4th Edition, p. 411 (McGraw-Hill, New York, 1978)

23. Ryder, E., Gregolin, C., Chang, H.-C., and Lane, M. D.: Liver acetyl CoA carboxylase: insight into the mechanism of activation by tricarboxylic acids and acetyl CoA. Proc. Natl. Acad. Sci., 57: 1455 (1967).

24. Scriver, C. R., and Rosenberg, L. E.: In: Amino Acid Metabolism and Its Disorders (W. B. Saunders, Philadelphia, 1973).

25. Siegel, L., Foote, J. L., and Coon, M. J.: The enzymatic synthesis of propionyl coenzyme $A$ holocarboxylase from d-biotinyl $S^{\prime}$-adenylate and the apocarboxylase. J. Biol. Chem., 240: 1025 (1965).

26. Tanaka, K., Armitage, I. M., Ramsdell, H. S., Hsia, Y. E., Lipsky, S. R., and Rosenberg, L. E.: $\left[{ }^{13} \mathrm{C}\right]$ valine metabolism in methylmalonicacidemia using nuclear magnetic resonance: propionate as an obligate intermediate. Proc. Natl. Acad. Sci., 72: 3692 (1975).

27. Udenfriend, S., Stein, S., Bohlen, P., Dairman, W., Leimgruber, W., and Weigele, M.: Fluorescamine: a reagent for assay of amino acids, peptides, proteins, and primary amines in the picomole range. Science, 178: 871 (1972).

28. Wang, C. S., and Smith, R. L.: Lowry determination of protein in the presence of Triton X-100. Anal. Biochem., 63: 414 (1975).

29. The authors thank Ms. Rosalie Blunden for valuable technical assistance. For purposes of cross-reference with other publications, we shall provide our laboratory numbers used to identify cell lines from the seven PCC-deficient patients, followed by their initial in parentheses: 49 (A. G.); 68 (N. B.); 94 (G. S.); 117 (R. H.); 148 (P. C.); 269 (N. M.); and 270 (K. M.).

30. This research was supported in part, by a research grant to L. E. R. from the National Institute of Arthritis, Metabolic and Digestive Diseases.

31. The present address of Dr. Hsia is: Department of Genetics, University of Hawaii at Manoa, Honolulu, Hawaii 96822 (USA).

32. Requests for reprints should be addressed to: Leon E. Rosenberg, M. D., Yale University School of Medicine, Department of Human Genetics, New Haven, Connecticut 06510 (USA).

33. Received for publication April 18, 1978.

34. Accepted for publication June 8,1978 . 